\title{
Arzoxifene Hydrochloride
}

National Cancer Institute

\section{Source}

National Cancer Institute. Arzoxifene Hydrochloride. NCI Thesaurus. Code C2460.

The hydrochloride salt of arzoxifene, a synthetic aromatic derivative with anti-estrogenic properties. Arzoxifene binds to estrogen receptors as a mixed estrogen agonist/antag onist. In comparison to other selective estrogen receptor modulators (SERMs), arzoxifene exhibits greater bioavailability and higher anti-estrog enic potency in the breast than raloxifene; it exhibits reduced estrogenicity in the uterus compared with either tamoxifen or raloxifene. This agent may have beneficial effects on bone and the cardiovascular system. 